\title{
PROFESSOR PESQUISADOR - EDUCAÇÃO CIENTIIFICA: O ESTÁGIO COM PESQUISA NA FORMAÇÃO DE PROFESSORES PARA OS ANOS INICIAIS
}

\author{
Teacher researchers and science education: \\ research stage in early years' teacher education
}

Caroline Barroncas de Oliveira $^{1}$ • Amarildo Menezes Gonzaga ${ }^{2}$

\begin{abstract}
Resumo: Pesquisa desenvolvida durante período de estágio de docência, na disciplina Pesquisa e Prática Pedagógica II, no $9^{\circ}$ período do curso de licenciatura em Pedagogia da Escola Normal Superior da Universidade do Estado do Amazonas, centrada no seguinte problema de investigação: como contribuição para a consolidação da educação científica, que impactos um plano de ação pode gerar na formação de professores para os anos iniciais, considerando-se, prioritariamente, as possibilidades de ressignificação da concepção de professor pesquisador centrada na articulação entre estágio-pesquisa? Os fundamentos do percurso metodológico foram subsidiados pela pesquisa participante, consolidada a partir de um plano de ação, constituído de quatro fases: diagnóstico, elaboração, execução e avaliação. Constatou-se que a formação do professor pesquisador, quando ressignificada a partir da concepção do estágio com pesquisa, é uma alternativa inovadora e capaz de contribuir no desenvolvimento da educação científica, em processos de formação de professores.
\end{abstract}

Palavras-chave: Formação de professores. Educação em ciência. Pesquisa. Estágio. Ensino Superior.

\begin{abstract}
This research was performed during the probationary period in teaching while attending the course Research and Pedagogical Practice II. It was part of the 9th semester in the graduation degree of Pedagogy at Escola Normal Superior of the University of Amazonas. It was centered on the following research problem: as a contribution to science education, how could teacher education (of those teaching in the early school years) reframe the concept of teacher researcher centered on the relationship between teacher training and research? The methodological issues were based on participant research which came together with an action plan of four phases: diagnostic, design, implementation and evaluation. It showed how the education the teacher- researcher receives, could take on a new view of research that develops hand in hand with practice, and is an innovative alternative. Besides, it can contribute to the development of scientific education in teacher training processes.
\end{abstract}

Keywords: Teacher training education. Science education. Research. Training. Higher education.

1,2 Grupo de Estudo sobre Questões Educacionais Amazônicas (GEQEAM), Escola Normal Superior (ENS), Universidade do Estado de Amazonas (UEA). Rua Damasco, n. 24, Conjunto Campos Elíseos-Planalto. Manaus, AM, Brasil.69.045-070. carol_barroncas@yahoo.com.br 
Oliveira, C. B.; Gonzaga, A. M.

\section{Introdução}

Esta pesquisa decorreu de uma opção de vida no último ano do Ensino Médio, quando decidimos prestar vestibular para a licenciatura em Normal Superior. Durante essa formação inicial que experienciamos, tivemos a oportunidade de conhecer e vivenciar a proposta de estágio articulado à pesquisa, embasada na concepção do professorpesquisador. Um dos fatores determinantes do respectivo processo formativo foi termos perpassado por caminhos tortuosos na legitimação da formação científica, em função tanto dos desafios pessoais, quanto institucionais. Apesar disso, construímos um olhar diferenciado sobre a organização do trabalho pedagógico, uma vez que não conseguimos dissociar dos subsídios que dão sentido àquele a educação científica como mola propulsora na legitimação da identidade docente.

Quando ingressamos no mestrado profissional em Ensino de Ciências na Amazônia, da Universidade do Estado do Amazonas, uma vez que não tínhamos experiência na docência do Ensino Superior, especificamente na disciplina Pesquisa e Prática Pedagógica, no curso de Pedagogia, a qual foi ministrada pelo nosso orientador, vimo-nos perante um grande desafio: dar sentido à educação científica no próprio processo de educação científica pelo qual passavam os estudantes que cursavam a disciplina em questão, visto que a proposta do projeto pedagógico do curso era, também, similar à nossa formação inicial, direcionada para a articulação do estágio com a pesquisa na perspectiva do professor pesquisador. Além disso, a própria circunstância era favorável para essa atitude, pois estavam em fase de elaboração dos seus trabalhos de conclusão de curso.

Decorrente do exposto, surgiu o seguinte problema, que nos propusemos a investigar: como contribuição para a consolidação da educação científica, que impactos um plano de ação pode gerar na formação de professores para os anos iniciais, considerando-se prioritariamente as possibilidades de ressignificação da concepção de professor pesquisador centrada na articulação entre estágio-pesquisa?

Como resultado do percurso investigativo que fizemos, apresentamos, sucintamente, neste artigo, dividido em duas sessões distintas e complementares: a) a educação científica e a formação do professor pesquisador; b) o percurso investigativo da pesquisa. Por fim, algumas considerações são apresentadas a respeito da proposta de formação de professores pesquisadores articulando-se estágio e pesquisa como elementos norteadores na legitimação da educação científica.

\section{A educação científica e a formação do professor pesquisador}

A educação científica, por se constituir em uma área da educação que envolve problemas peculiares, distingue-se de outros campos de referência da escola. Dentre as peculiaridades, está o sentido que precisa ser dado a ela no processo de formação de professores, a fim de que, de fato, possa existir uma escola que viabilize um ensino instigante, crítico e desafiador. Logo, ressaltamos a importância da formação do professor pesquisador, como referencial norteador do processo de legitimação da educação científica.

$\mathrm{Na}$ construção do referencial teórico que deu sentido à nossa compreensão da educação científica, articulamos conceitos, dialogando com teóricos que tratam sobre educação e 
educação científica, especificamente no Brasil; tendências na formação de professor, professor reflexivo/pesquisador; professor pesquisador como elemento norteador para a legitimação da educação científica; e, por último, a necessária articulação entre estágio e pesquisa.

No processo de construção das bases teóricas mencionadas, em princípio, consideramos imprescindível evidenciar que a educação científica desenvolve habilidades, define conceitos e conhecimentos, estimulando o estudante a observar, questionar, investigar e entender, de maneira lógica, os seres vivos, o meio em que vivem e os eventos do cotidiano. Além disso, estimula a curiosidade, a imaginação e o entendimento do processo de construção do conhecimento, logo, investir no conhecimento científico contribuirá para que os seus resultados estejam ao alcance de todos (ROITMAN, 2007).

Quando dialogamos com Vale (2005), convencemo-nos da necessidade de explicar que o objetivo principal da educação científica é ensinar ciência e técnica de modo significativo e interessante, a todos indistintamente, atendendo à quantidade (todas as camadas sociais) com qualidade (com ensino centrado na compreensão do fato científico). Em outras palavras, é colocar a prática social como ponto de partida e de chegada da própria educação científica, tomando o contexto como fonte de inspiração para a determinação dos conteúdos científicos e técnicos a serem trabalhados pela comunidade escolar sob orientação e mediação do professor, criando condições para a formação do espírito científico. Logo, há necessidade de ações mais intensas no processo em questão, para que sejam formados profissionais com efetiva consciência de cidadania, com independência de pensamento e capacidade crítica adquiridos ao longo da escolarização.

No movimento em questão, a tônica incide em contribuir para a formação de cidadãs e cidadãos que não só saibam ler melhor o mundo onde estão inseridos, como também sejam capazes de transformar este mundo para melhor. Sendo assim, explorar as formas de ler a natureza a partir da ciência, por meio da leitura política, considerando a história da ciência o método de ensino, cuja referência está na própria ciência, na condição de caminho para efeito de legitimação da educação científica (CHASSOT, 2006).

Tendo-se a graduação como contexto da pesquisa, ainda é comum presenciarmos, em pleno século XXI, currículos de formação de professores que privilegiam a memorização de informações, em detrimento do entendimento e da aprendizagem. Inclusive, Amabis (2005) enfatiza que, mesmo com o incentivo das bolsas de iniciação científica, o fator contribuinte para a má-formação científica dos universitários ainda é a ausência de atividades de pesquisa. Dessa forma, faz-se necessário combinar ensino e pesquisa, pois a prática da pesquisa científica como alternativa, com todas as suas incertezas e dificuldades, tende a fornecer ao estudante certa noção de como funciona a ciência, auxiliando-o a se manter distante dos dogmas na compreensão do que ocorre no cotidiano do seu próprio processo formativo.

Além disso, na atual conjuntura, mais do que nunca, reivindica-se: por uma escola transformadora, liberando a criatividade e a alegria da descoberta, de forma a possibilitar um ensino instigante e desafiador por meios de novos métodos de educação científica; por uma escola que ensine o aluno a pensar e refletir, que seja uma agência de cultura, de desenvolvimento da cidadania e de mudanças (WERTHEIN; CUNHA, 2005). A partir disso, faz-se necessário repensar o trabalho pedagógico do professor, e uma das oportunidades é problematizar o ensino articulado com a pesquisa em processos de formação de professores, evidenciando qual tendência formativa incide como elemento norteador e imprescindível na legitimação da educação científica. A respeito disso, trataremos a seguir. 
García e Porlán (2000), ao discutirem os modelos de formação de professores em ciências, apresentam a formação investigativa como proposta, defendendo a ideia de que o professor investigador é uma síntese teórica que resume e encerra os fundamentos do modelo de formação e os fins estratégicos que se pretendem como princípio prático que orienta a formulação e a experimentação de propostas na formação de professores de ciências.

Tal proposta envolve as seguintes atividades formativas e avaliadoras: descrição e análise - com a formulação de problemas e dilemas que caracterizam o currículo de ciências na ação: tomada de consciência das concepções científicas e didáticas próprias em relação à problemática; contraste crítico, reflexivo e argumentado entre as concepções próprias, a de outros professores e as precedentes; estruturação dos significados construídos - com a sistematização do novo saber prático em forma de propostas de intervenção curricular que abordem a problemática proposta, aplicação experimental e seguimento avaliativo das hipóteses construídas e meta-reflexão em duplo sentido - com a tomada de consciência e sistematização das mudanças ocorridas no saber prático e na ação dos professores, e o contraste das mudanças com a hipótese de progressão profissional.

De modo geral, considerando as diferenças de enfoques entre as abordagens teóricometodológicas, o movimento de formação do professor pesquisador configura-se na expressão do reconhecimento da importância da pesquisa na formação e no trabalho docente, considerando o papel ativo e crítico do professor como o sujeito investigador. Esse movimento de caráter político, social e epistemológico pode representar uma das estratégias de ressignificação do trabalho do professor, ou seja, a partir de uma formação específica, esse professor investigaria e produziria explicações sobre o ensino e a realidade educativa entendida como prática social.

Essa perspectiva de formação defende a possibilidade da pesquisa no desenvolvimento do trabalho pedagógico como instrumento de construção da autonomia do professor, emergindo a partir das múltiplas possibilidades de produção e reconstrução de saberes, gerando mudanças significativas tanto na postura quanto na cultura caracterizadora do processo de construção do conhecimento e da própria identidade do contexto em que a respectiva formação acontece. Em outras palavras, quando mediada pela pesquisa, a formação do professor pode representar estratégia de produção de conhecimento, desenvolvimento profissional e mudança da prática docente, uma vez que, ao se rejeitar a perspectiva de professor como consumidor de conhecimento acadêmico, transmissor e implementador do ensino, reconhece-se a capacidade investigadora tanto da sua prática pedagógica quanto da realidade em que se insere.

Outro aspecto importante a respeito da perspectiva em evidência incide no fato de que aquela questiona a visão instrumental da prática e propõe a articulação entre conhecimento e ação, entendendo-os como integrantes de um mesmo processo. Pretende-se, a partir dela, uma formação "[...] de professores que produzam conhecimentos sobre o pensar e fazer docentes, de modo que o desenvolvimento dessas atitudes e capacidades permita-lhes reconstruir saberes, articular conhecimentos teóricos e práticos e produzir mudanças no trabalho docente" (LISITA; ROSA; LIPOVETSKY, 2004, p. 109-110).

Logo, o papel do professor muda de foco e se dirige para a produção de conhecimentos e a construção da sua autonomia profissional.

Ressaltamos, também, a respeito da perspectiva em questão, o que expressa Severino (2008), quando nos esclarece que a formação do professor pesquisador não se trata de formar 
o professor no pesquisador especializado, mas de praticar a docência mediante a postura investigativa, derivada de uma contínua atividade de busca. Para efeito de sustentação dessa proposição, o professor precisa manter-se envolvido com a pesquisa por dois motivos: primeiro, para acompanhar o desenvolvimento histórico do conhecimento; segundo, porque o conhecimento só se realiza como construção de objetos. Logo, o que está em pauta é uma concepção de aprendizagem como processo de construção de conhecimentos, isto é, que a própria prática da pesquisa seja o caminho do processo ensino-aprendizagem.

Numa formação de professor vinculada à pesquisa, exige-se o envolvimento dos alunos em procedimentos de produção do conhecimento científico, cuja articulação entre formação científica e aprendizagem teórica precisa ser objetivada pela academia. Referente a essa questão, ainda corrobora conosco Severino (2008), quando considera os procedimentos pertinentes à modalidade da iniciação científica como os mais pertinentes para que se possa realizar a aprendizagem mais significativa, preparando os alunos que passam por aquela experiência para edificação das bases na continuidade de sua vida científica, cultural e acadêmica, de modo geral.

Com isso, podemos verificar que a iniciação à prática científica na formação inicial exige mediações curriculares que articulem uma legitimação "político-educacional, epistemológica, estratégia didático-metodológica e uma metodologia técnica aplicada" (SEVERINO, 2008, p. 24). Portanto, é necessário que ocorram articulações entre as dimensões teóricoepistemológicas, prático-metodológicas e político-educacionais, para que intervenham ao longo do processo formativo.

Severino (2008) também comenta que é preciso aprender a pesquisar pesquisando e, como exercício desse ato, destaca a iniciação científica e o trabalho de conclusão de curso (TCC) como duas modalidades que envolvem a atuação concreta da investigação.

Especificamente a respeito da modalidade TCC, como exercício articulador entre a pesquisa e a realidade escolar na formação inicial, cujo foco evidencia-se na pesquisa que foi desenvolvida e caracteriza esse trabalho, destacamos que tende a possibilitar ao discente perceber que a prática atualiza e interroga a teoria (GHEDIN, 2007). Nesta perspectiva, a formação do professor pesquisador, enquanto sujeito da construção do seu próprio conhecimento, inicia-se ainda na proposta do estágio articulado à pesquisa no processo de formação científica.

Referente ao estágio, ressaltamos que, conforme Pimenta e Lima (2004), o movimento de valorização da pesquisa no estágio no Brasil teve sua origem no início dos anos 1990, a partir do questionamento sobre a indissociabilidade entre teoria e prática no campo da didática e da formação de professores. Daí a necessidade de se articular o estágio curricular à pesquisa no campo educacional.

Ludke e André (1986), por sua vez, partilham da compreensão de que os elementos práticos vivenciados nos estágios devem subsidiar a produção de conhecimento para o campo educacional. Logo, o estágio coloca-se como eixo articulador entre teoria e prática, já que os elementos da prática são trazidos pelos estágios e reelaborados nos cursos de formação docente, garantindo a produção de conhecimento nas áreas específicas da docência.

Conforme discute Piconez (2002), a prática de ensino sob a forma de estágio supervisionado é, na verdade, um componente teórico-prático. Isto é, a vivência dos alunos estagiários nas escolas traz elementos da realidade para análise e reflexão. Os problemas são sempre atuais, reais, muitas vezes repetidos, até que o olhar curioso do pesquisador lance sobre eles suas indagações 
científicas, suas reflexões e estudos, e se comece a produzir conhecimento sobre os elementos da realidade: esse é o movimento que a pesquisa suscita e que o estágio permite que seja, ao mesmo tempo, teórico e prático no processo de construção de conhecimento científico.

Esse processo de investigação da realidade escolar a partir de matizes científicas, promovido pelos estágios supervisionados, além de contribuir para a (re)construção de conhecimento nos campos específicos do ensino e da aprendizagem, transforma o aluno/pesquisador em autor de propostas teóricas, que podem ser avaliadas pelas escolas e por seus pares na academia, a fim de se constituírem em propostas metodológicas para as atividades escolares. É uma "postura investigativa que favorece a construção de projetos de pesquisa a partir do estágio" (PIMENTA; LIMA, 2004, p. 55-56).

Desta forma, acredita-se que a formação do professor pesquisador, que possibilita a construção destas habilidades científicas durante o processo de formação, com a articulação entre o estágio e a pesquisa, poderá contribuir para a educação científica; e, consequentemente, a postura desse professor, no cumprimento de sua profissão, contribuirá, tanto para si quanto para seu alunado, na formação do senso crítico, reflexivo e científico - elementos imprescindíveis na construção da cidadania.

Para dar sentido ao percurso investigativo que fizemos, pautamo-nos na pesquisa participante, que foi realizada, conforme comentamos anteriormente, durante o nosso período de estágio de docência do mestrado. É a respeito do que trataremos a seguir.

\section{O percurso investigativo da pesquisa}

O percurso investigativo foi pautado na Pesquisa Participante (PP), que consiste em um enfoque de investigação social, por meio do qual se busca plena participação da comunidade na análise de sua própria realidade, com objetivo de promover a participação social para o benefício dos participantes da investigação. Trata-se, portanto, de uma atividade educativa de investigação e ação social (BRANDÃO, 1984). Considerando os princípios da PP, estivemos diante de uma teia de significados, percepções e sentimentos atrelados ao processo investigativo, caracterizando, assim, uma abordagem qualitativa, pois "decorre a ênfase na busca de dados qualitativos que venham a denotar significados, elementos importantes na compreensão do fenômeno" (GHEDIN; FRANCO, 2008, p. 114).

$\mathrm{Na}$ legitimação da PP, sentimos necessidade de ressaltar a importância da descrição da realidade observada e dos significados atribuídos pelas pessoas que pertencem a tal realidade. Para tanto, optamos por trabalhar com narrativas, que na pesquisa e/ou no ensino implica ao pesquisador trabalhar uma relação dialógica entre suas experiências vivenciadas e as experiências dos sujeitos de pesquisa e/ou ensino, num constante processo de (re)construção da trajetória percorrida, atribuindo-lhe novos significados. Nesse sentido, pode-se dizer que: "Ao mesmo tempo em que se descobrem no outro, os fenômenos revelam-se em nós" (CUNHA, 1997, p. 34).

A pesquisa narrativa foi utilizada por possibilitar o discurso permeado das nossas vivências durante o processo de (re)construção do conhecimento no estágio de docência, tanto pelos sujeitos quanto pela pesquisadora, no intuito de viabilizar a consolidação da educação científica na formação de professores para os anos iniciais, por meio do professor pes- 
quisador e da proposta do estágio-pesquisa. Por conseguinte, trechos narrativos no texto dissertativo mostrarão o que vivenciamos a partir da observação participante, auxiliada com a aplicação de questionários.

Conforme mencionamos, os sujeitos envolvidos foram os estudantes do $9^{\circ}$ período do curso de licenciatura em Pedagogia que cursaram a disciplina Pesquisa e Prática Pedagógica II-TCC, no turno noturno, na Escola Normal Superior, na Universidade do Estado do Amazonas. Na disciplina mencionada, matriculou-se um total de 43 estudantes, mas a assiduidade foi de 38. Era uma turma que se encontrava em uma situação atípica, uma vez que eram todos oriundos do curso normal superior, e estavam passando por um "processo migratório" para o curso de licenciatura em Pedagogia. Com a "migração", alguns estudantes tiveram dificuldades em conciliar as suas experiências de estágio docência com as pesquisas que desenvolveram para os seus trabalhos de conclusão de curso, descaracterizando a proposta formativa referendada pela concepção de professor pesquisador que norteara os projetos de ambos os cursos mencionados.

No contexto em que ocorreu a pesquisa, foi desenvolvido o seguinte percurso investigativo, de acordo com a Figura 1.

Figura 1. Percurso do plano de ação construído em parceria com os estudantes

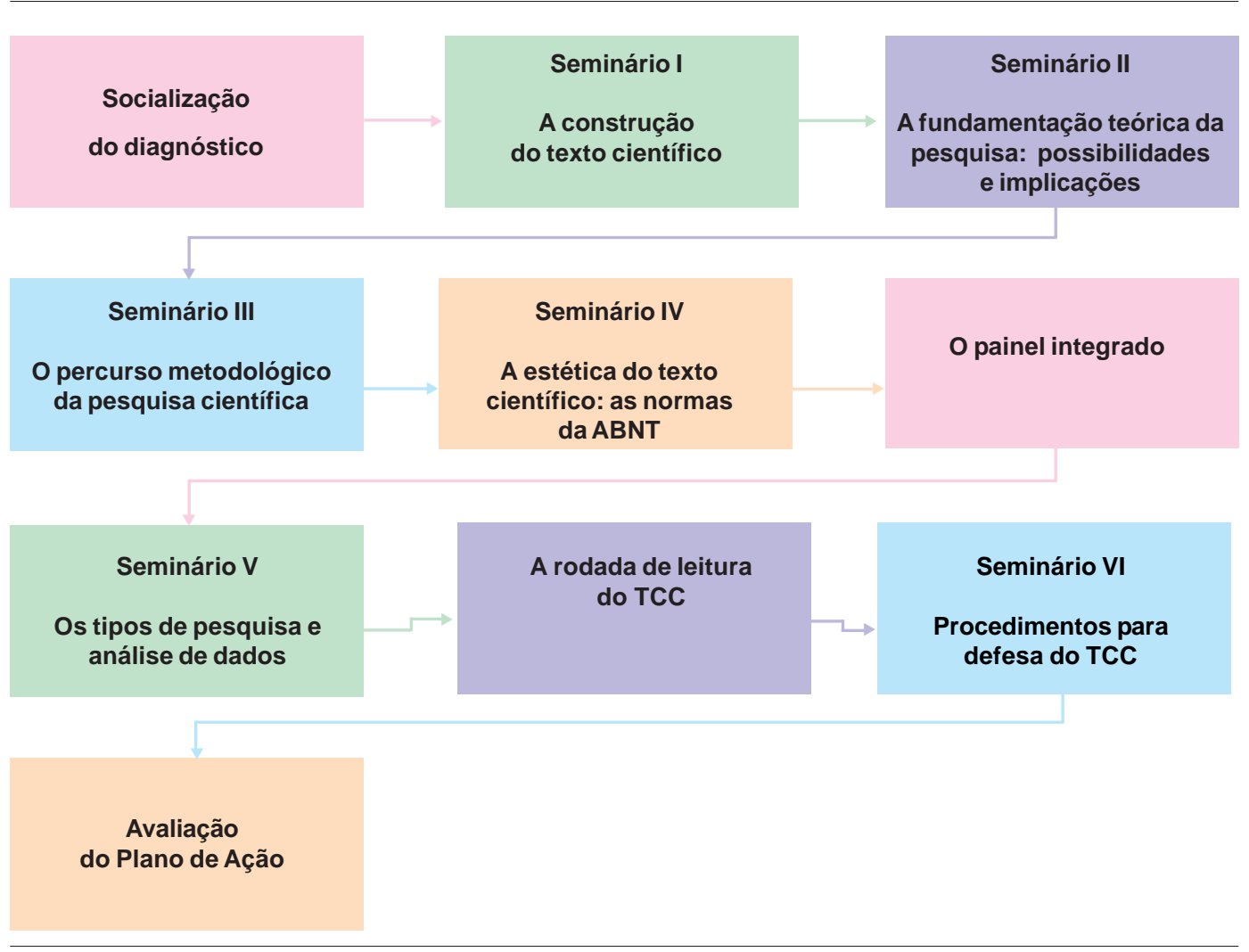

Fonte: Oliveira (2010). 
Oliveira, C. B.; Gonzaga, A. M.

(a) O diagnóstico: realizado no momento em que adentramos na turma dos licenciandos do nono período, quando iniciamos o estágio-docência. Nossa principal intenção foi levantar dados para descobrir as considerações prévias deles em relação tanto à concepção do professor pesquisador quanto a compreensão que eles tinham deles próprios no processo formativo pelo qual passavam na modalidade estágio-pesquisa. Aproveitamos detalhes a respeito dos sentimentos que experienciaram, levando-os a se sentirem como sujeitos que passavam por um processo de pesquisa que tende a contribuir na consolidação da Educação Científica.

Durante essa fase, detectamos a dificuldade que os estudantes tinham em articular os aspectos referentes à estrutura de seus trabalhos, como: tema, problema, questões norteadoras, objetivos e procedimentos metodológicos. Inclusive, esse foi o primeiro referencial que obtivemos para elencar no conjunto das atividades do Plano de Ação.

Nesse momento, pautando-nos em outros aspectos, além dos mencionados, aproveitamos, ainda durante a socialização do diagnóstico, para expor e discutir a respeito de algumas concepções prévias referentes à dinâmica da pesquisa científica. Em virtude disso, fizemos alguns questionamentos em relação ao que foi exposto e à situação real de suas pesquisas. Muitos deles ficaram alguns minutos pensando e, aos poucos, participaram verbalizando sobre a real situação do andamento das suas pesquisas.

(b) A elaboração e execução do Plano de Ação: inicialmente, apresentamos o "esboço" de um plano, que foi visualizado pelos estudantes com certa inibição, mas, mesmo assim, acabaram expressando os seus sentimentos em relação ao que estávamos nos propondo a realizar. À medida que os indagávamos, íamos definindo as atividades, justificando a relevância de cada uma delas, traçando os seus objetivos e as respectivas estratégias para atingilos, definição de datas, possíveis responsáveis e procedimentos avaliativos para cada uma delas. Conforme avançávamos na negociação das ideias para a construção do documento, apareciam divergências de opiniões e, curiosamente, as divergências geravam sugestões por parte dos próprios estudantes. Além disso, de acordo com as situações interativas, não nos esquecíamos de chamar a atenção para a responsabilidade que todos precisariam assumir no que se estava propondo. Esse procedimento ajudou-os na motivação de suas arguições e colaboração, efetivando-se na preocupação tanto com os resultados dos seus desempenhos no plano individual quanto no coletivo. Apesar de nem todos os estudantes terem participado efetivamente, acabaram demonstrando, em suas expressões faciais, que estavam tentando compreender a dinâmica do percurso apresentado, atípica ao que se propõe para o desenvolvimento da maioria das disciplinas.

Como resultado da elaboração do plano de ação, ficaram definidas as seguintes ações norteadoras: Seminário I (A construção do texto científico), Seminário II (A fundamentação teórica da pesquisa: possibilidades e implicações), Seminário III (O percurso metodológico da pesquisa científica), Seminário IV (A estética do texto científico: as normas da ABNT), o painel integrado; Seminário V (Os tipos de pesquisa e a análise dos dados), a rodada de leitura de TCCs, Seminário VI (Procedimentos para defesa do TCC).

A primeira ação - Seminário I, cujo tema foi "A construção do texto científico" - teve como objetivo ampliar os conhecimentos na produção científica, para efeito de contribuição na construção do TCC. Foi coordenada por um dos docentes do quadro permanente do mestrado profissional em Ensino de Ciências na Amazônia, da Universidade do Estado do Amazonas. Centrou a discussão em torno de sua experiência quanto a algumas dissertações e teses 
que orientou: a relação entre o pesquisador e o texto científico; a diferenciação da escrita poética e da escrita dissertativa; a originalidade dos títulos monográficos; a tríade introdução, desenvolvimento e conclusão; a revisão crítica do texto científico a partir de um terceiro olhar.

A segunda ação - Seminário II, intitulado "A fundamentação teórica da pesquisa: possibilidades e implicações" - foi coordenada por uma egressa do mestrado profissional em Ensino de Ciências na Amazônia, da Universidade do Estado do Amazonas. Focou a discussão nas possibilidades e implicações de construção da fundamentação teórica e sua importância no trabalho de pesquisa, a partir da sua própria experiência investigativa durante o período em que cursou o mestrado. Orientou a respeito: dos procedimentos acadêmicos básicos a serem adotados na análise de obras, da clareza e da articulação entre fundamentação teórica e o problema de pesquisa - para efeito de contribuir na construção do primeiro capítulo do trabalho de pesquisa dos estudantes, ou seja, o TCC. Especificamente, também abordou, durante sua exposição, sobre:

. o que é a fundamentação teórica, considerando teoricamente sua definição;

- como é que podemos fazer uma fundamentação teórica, a partir do surgimento de categorias da problemática;

- a construção do pré-sumário, sendo este o momento de saber se o que se pretende escrever vai dar consistência ao problema da pesquisa.

O objetivo da terceira ação - Seminário III "O percurso metodológico da pesquisa científica" - foi elucidar a construção da metodologia da pesquisa com suas respectivas técnicas e abordagens, para efeito de contribuir na elaboração do segundo capítulo do TCC dos estudantes. Foi também convidado, para dar sua contribuição, um egresso da primeira turma do mestrado profissionalizante em Ensino de Ciências na Amazônia, decorrente de ter passado pela experiência na sua formação inicial a partir da perspectiva do professor pesquisador que articula o estágio à pesquisa, assim como de ter, na sua pesquisa da formação continuada no mestrado mencionado, centrado o problema que investigou naquela mesma perspectiva. Abordou os seguintes aspectos: a relação entre orientador e orientando - parceria para realizar um trabalho de qualidade; importância do projeto de pesquisa para a elaboração do TCC; coerência entre objeto e problema; sincronia entre método, abordagem e tipo de pesquisa; clareza dos objetivos; abordagem qualitativa e quantitativa; técnicas de pesquisa (entrevista, questionário, observação, análise documental); instrumentos de pesquisa (diário de campo, câmera fotográfica, gravador de voz, roteiro e formulário).

A quarta ação - Seminário IV, cujo tema foi "A estética do texto científico: as normas da ABNT" - objetivou esclarecer a estética do texto científico, para efeito de auxiliar os estudantes na formatação do TCC. A professora pesquisadora convidada, inicialmente, enfatizou a importância de, na estética do texto, não se valorizar em excesso as normas, em detrimento do conteúdo. Por conseguinte, destacou alguns elementos que precisam ser considerados na construção da introdução, do desenvolvimento e da conclusão do texto dissertativo. Destacou também, conforme as orientações da ABNT, aspectos que precisam ser considerados em relação à formatação, como: a estrutura do resumo, o tipo de tratamento a ser dado para as citações direta e indireta, à numeração progressiva, ao espacejamento, às referências e à apresentação gráfica.

O painel integrado - ou a quinta ação - foi iniciado a partir da técnica Discussão em pequenos grupos. Os pontos analisados foram: ressignificação de conhecimentos a partir do 
desenvolvimento de sua pesquisa e o processo de formação inicial; impressões desse momento de construção da pesquisa científica a partir da formação de professores para os anos iniciais que articula o estágio com a pesquisa; sugestões de melhorias para a formação do professor pesquisador, que articula o estágio com pesquisa; impactos das atividades desenvolvidas no plano de ação para a formação científica dos estudantes, considerando a elaboração do TCC. Posteriormente, os pequenos grupos discutiram cada um dos temas mencionados e elaboraram suas respectivas sínteses, que foram explanadas por cada um dos representantes dos grupos, no momento em que representaram os seus pequenos grupos, nos grupos de interação. Por fim, retornaram aos seus grupos de origem e socializaram a experiência que vivenciaram.

Esta atividade reflexiva com os estudantes proporcionou-lhes subsídios para discutirem sobre que elementos realmente queriam acrescentar na construção tanto da sua condição humana quanto da sua identidade profissional. Ao final dessa ação, chamou-nos atenção uma fala de um dos estudantes, quando disse o seguinte: "A atividade realizada foi bastante produtiva, pois tivemos uma autocrítica da realidade de cada aluno com o seu tema", respaldando a validade da proposta desenvolvida.

A sexta ação - o Seminário V, intitulado "Os tipos de pesquisa e a análise dos dados" - foi planejada com o intuito de se possibilitarem melhorias no aspecto metodológico das pesquisas dos estudantes, bem como esclarecer os mecanismos investigativos que o professor pesquisador necessita para sua prática educativa. Este seminário foi ministrado por nós, e contou com o auxílio do próprio professor que ministrou a disciplina Pesquisa e Prática Pedagógica II, o qual nos acompanhou tanto no estágio de docência quanto na orientação dessa pesquisa. Os assuntos abordados neste seminário foram sobre: procedimentos essenciais na metodologia da pesquisa; método; tipos de pesquisa (experimental, exploratória, descritiva, narrativa, etnográfica, pesquisa-ação, pesquisa participante, documental e bibliográfica); enfoques analíticos (análise de conteúdo, análise argumentativa, análise do discurso, análise da conversação e da fala).

A sétima ação - Rodada de leituras - foi planejada em parceria com os estudantes, no último encontro que tivemos. O professor da disciplina, juntamente conosco, organizou a turma em quatro grupos com sete pessoas cada, totalizando 28 estudantes, para o desenvolvimento dessa técnica, que teve como objetivos: trocar experiências sobre a construção do texto, como também melhorar a elaboração do primeiro capítulo a partir das informações obtidas nos seminários realizados. O desenvolvimento consistiu na troca de textos referentes ao primeiro capítulo. Cada um lia o texto do colega e emitia um parecer em uma ficha avaliativa. Feitas todas as leituras e respectivas emissões de pareceres, organizamos apenas um único grupo para que todos socializassem as fortalezas e debilidades mais presentes e diagnosticadas durante o processo avaliativo.

O Seminário VI, que correspondeu à oitava ação, cujo tema foi "Procedimentos para Defesa do TCC", teve como objetivo conhecer os procedimentos básicos e necessários para a defesa do TCC, enquanto postura, e os processos técnicos de apresentação científica. Este seminário culminou no fechamento das atividades do plano de ação. Os assuntos abordados foram: elementos na elaboração do TCC escrito conforme a legislação do curso; roteiro para construção da apresentação oral conforme o tempo destinado; forma de apresentação do referencial teórico, metodologia e análise de dados; defesa oral: postura e a forma de falar; defesa das ideias; recomendações: movimentos de links e dos slides; ensaio prévio para orientador. 
Após a apresentação sucinta das etapas executadas do plano de ação, descreveremos os resultados obtidos da sua respectiva avaliação na unidade seguinte. Decidimos pelo recorte de constatações referentes às diferentes etapas, como partes do experienciado pelos sujeitos na caracterização do percurso investigativo em questão.

(c) A avaliação do plano de ação: ainda na construção do diagnóstico e no percurso investigativo, foram detectadas as dificuldades básicas pelas quais os estudantes passaram na compreensão do próprio processo de formação inicial, o qual tem, como referência, a concepção de professor pesquisador a partir do estágio com pesquisa. Muitas das dificuldades contradizem o que está vigente no projeto pedagógico do curso de licenciatura em Pedagogia da Escola Normal Superior da Universidade do Estado do Amazonas, que tem como objetivo geral formar o professor, o profissional reflexivo, capaz de compreender e atuar na realidade contemporânea, propondo novas alternativas pedagógicas a partir da prática de estágio, tendo como base teórica a concepção do professor pesquisador. Mesmo assim, houve avanços, sobretudo quando alguns deles assim se posicionaram:

"Através da presença de outros professores e convidados, cuja multiplicidade de pensamentos acerca das ações de pesquisa auxiliou e muito, pois várias dúvidas que há tempos vinham se somando, foram dirimidas e por fim solvidas". (E4)

"[...] Posso afirmar que foi cursando esta disciplina que começamos realmente a entender melhor o processo de pesquisa. Infelizmente por todos aqueles fatores peculiares a nossa turma (os quais você conhece), tivemos acesso tardio a certas informações. Mas, sem dúvida foi uma honra participar deste momento conduzido com maestria por vocês". (E5)

A respeito dos impactos na ressignificação da concepção do professor.pesquisador e do processo de pesquisa gerados na execução do plano de ação, descobrimos que tanto nós quanto os estudantes obtivemos uma nova leitura e análise da formação inicial de professores, possibilitando-nos a ponderação da pesquisa como parte essencial do perfil identitário profissional e pessoal do professor. Concernente a esses impactos, por exemplo, especificamente sobre a dimensão existencial que construímos em nosso imaginário sobre a concepção de professor pesquisador, tivemos a oportunidade de descobrir que emergiram alternativas que nos levaram a mudanças significativas na forma de compreendermos a organização do trabalho pedagógico, uma vez que não conseguimos mais deixar de percebê-lo como extensão do processo de educação científica, capaz de contribuir para a contínua e constante reflexão do tipo de cidadania tanto pessoal quanto coletiva que estamos construindo. Assim pensamos sobretudo porque consideramos que a dimensão completa da vida e do trabalho de um professor, educador, intelectual, crítico e criativo, desdobra o seu trabalho pedagógico em todos os níveis, tendo o compromisso irrestrito com a inovação e a coragem de criar, transgredir e transformar dentro do seu trabalho cotidiano de docente.

Em relação à dimensão teórica e epistemológica, especificamente tratando-se do tema estágio com pesquisa, ficou evidente, entre os sujeitos da pesquisa, a importância de o estágio 
Oliveira, C. B.; Gonzaga, A. M.

ser um espaço de construção de conhecimento e que a pesquisa seja produtora daquele. Isto pode ser observado nas falas dos discentes ao agradecerem e confirmarem a importância dos assuntos abordados, mesmo que tardiamente, para os seus processos formativos. Para que essa dimensão seja legitimada, ficou evidente, nos comentários feitos pelos estudantes, a importância da necessária inserção do orientador e do aluno no ambiente escolar, ou seja, no "lócus" da pesquisa, para conhecer, refletir e analisar todos os aspectos possíveis, dando sentido àquela a partir do aperfeiçoamento de ser um professor pesquisador. Mesmo assim há os desafios que tendem a se repetir, e que são de ordem institucional, política e econômica, dificultando o processo. Dentre eles, foram destacados os seguintes: melhoraria do corpo docente em termos de competência e comprometimento; realização de mais concursos públicos para melhorar, cada vez mais, a qualidade do quadro docente; política de qualificação e valorização dos docentes; investimento em pesquisas etc. Assim, perguntamos: onde está o compromisso institucional da coordenação e dos professores em promover o estágio articulado à pesquisa? De que maneira os estudantes poderiam desenvolver o conhecimento teóricoprático da docência, uma vez que o estagiário tem a oportunidade de aprender os elementos constitutivos do saber científico em relação aos pedagógicos, e, além deste, com o saber daqueles que já estão na escola? (PIMENTA; LIMA, 2004).

Por fim, o processo de construção dos TCCs dos estudantes que foram sujeitos da pesquisa culminou efetivamente para suas respectivas defesas, o que pode ser considerado como êxito da experiência de pesquisa desenvolvida, que se deve tanto às contribuições dadas por nós, na disciplina Pesquisa e Prática Pedagógica II, quanto ao acompanhamento dos respectivos professores orientadores. As defesas dos estudantes aconteceram em dois dias $(22 \mathrm{e}$ 23 de dezembro de 2009). Ficou evidente, após as defesas, que os estudantes, de modo geral, conseguiram superar as dificuldades pelas quais passaram no processo de elaboração do TCC, demonstrando segurança e domínio teórico sobre as pesquisas que realizaram.

Ficou evidente também que os estudantes conseguiram articular os aspectos da dinâmica da pesquisa científica, mesmo com todas as dificuldades de ordem institucional e pessoal. Desta forma, aqueles futuros professores passaram a ter mais chances de se verem e de serem vistos, como afirma Giroux (1997), como profissionais de interesses políticos e ideológicos que estruturam relações sociais em sala de aula, a partir de valores consolidados em suas práticas educativas. A partir disso, não deixarão de assumir a condição de sujeitos transformadores, que poderão contribuir com a educação dos estudantes dos anos iniciais, orientando-os a se tornarem cidadãos ativos e críticos, conforme a educação científica exige.

\section{Considerações finais}

Retomamos, aqui, o problema que investigamos: como contribuição para a consolidação da educação científica, que impactos um plano de ação pode gerar na formação de professores para os anos iniciais, considerando-se prioritariamente as possibilidades de ressignificação da concepção de professor pesquisador centrada na articulação entre estágio-pesquisa?

Ao refletirmos a respeito do problema apresentado, tomamos ciência de que este não foi esgotado por completo, mas constatamos a contribuição da pesquisa participante a partir da utilização do plano de ação como um meio de colaborar para a compreensão, tanto por 
parte dos estudantes quanto nossa, da importância do estágio com pesquisa na formação inicial do professor pesquisador, uma vez que a pesquisa é valorizada não a partir do produto, mas do processo caracterizador da educação científica.

Outro detalhe constatado a partir da experiência do estágio com pesquisa na busca de consolidação da educação científica é a sua condição de momento ímpar entre o estabelecimento de articulações entre o que foi dito pelos professores em sala de aula, durante o processo de formação, com o que os professores, que atuam na docência, fazem no cotidiano das escolas, não apenas como um compromisso a ser cumprido por exigência do curso, mas como um momento de aprendizado de como é possível ser professor pesquisador, na articulação entre teoria e prática.

A respeito do que aprendemos com essa experiência, como professores pesquisadores que tiveram como objeto de estudo o estágio com pesquisa, e que simultaneamente fizeram estágio com pesquisa, tivemos a oportunidade de constatar que essa prática, além de ter contribuído para o nosso amadurecimento como professores, também ajudou-nos a compreender a sala de aula como um espaço de construção da cidadania, princípio básico da educação científica.

Constatamos que ganhamos maturidade e ampliamos o sentimento de pertencimento do sentir-se e do ser professor, especialmente a partir das incertezas, das dificuldades e dos medos experimentados durante o percurso, quando responsáveis pela condução de uma experiência alternativa na formação de estudantes, desde o planejamento, do domínio e da execução das atividades do plano de ação.

Foi assim que demos sentido e assumimos, na condição de professores pesquisadores, o estágio com pesquisa como uma causa, e, como cidadãos, acreditamos nesta alternativa como um viés possível de contribuir na legitimação da educação científica, imprescindível para uma sociedade e um mundo melhores.

\section{Referências}

AMABIS, J. M. A premência da educação científica. In: WERTHEIN, J.; CUNHA, C. da (Org.). Educação científica e desenvolvimento: o que pensam os cientistas. Brasília: UNESCO; Instituto Sangari, 2005. p. 141-146.

BRANDÃO, C. R. Pesquisa participante. São Paulo: Brasiliense, 1984.

CHASSOT, A. Alfabetização científica: questões e desafios para a educação. 4. ed. Ijuí: Editora Unijuí, 2006.

CUNHA, M. I. da. Conta-me agora!: as narrativas como alternativas pedagógicas na pesquisa e no ensino. Revista da Faculdade de Educação, São Paulo, v. 23, n. 1-2, Jan./ Dez. 1997. Disponível em: <http://www.scielo.br/scielo.php?script=sci_arttext\& pid=S0102-25551997000100010\&lng=en\&nrm=iso\&tlng=pt $>$. Acesso em: 10 set. 2009.

GARCÍA, J. E.; PORLÁN, R. Ensino de ciências e prática docente: uma teoria do conhecimento profissional. In: HARRES, J. B. S. (Org.). Ensino de ciências: teoria e prática docente. Lajeado: Univates, 2000. p. 15-23. 
Oliveira, C. B.; Gonzaga, A. M.

GHEDIN, E. (Org.). Perspectivas em formação de professores. Manaus: Valer, 2007.

GHEDIN, E.; FRANCO, M. A. S. Questões de método na construção da pesquisa em educação. São Paulo: Cortez, 2008.

GHEDIN, E. ; LEITE, Y. U. F. Formação de professores: caminhos da prática. Brasília: Líber, 2008.

GIROUX, H. A. Os professores como intelectuais: rumo a uma pedagogia crítica da aprendizagem. Porto Alegre: Artes Médicas, 1997.

LISITA, V.; ROSA, D.; LIPOVETSKY, N. Formação de professores e pesquisa: uma relação possível? In: ANDRÉ, M. O papel da pesquisa na formação e na prática dos professores. 3. ed. Campinas: Papirus, 2004. p. 107-115.

LUDKE, M.; ANDRÉ, M. Pesquisa em educação: abordagens qualitativas. São Paulo: EPU, 1986.

OLIVEIRA, C. B. de. Professor pesquisador-educação científica: o estágio com pesquisa na formação de professores para os anos iniciais. 2010. 242 f. Dissertação (Mestrado em Educação e Ensino de Ciências na Amazônia) - Escola Normal Superior, Universidade do Estado do Amazonas, Manaus, 2010.

PICONEZ, S. C. B. A prática do ensino e o estágio supervisionado. 10. ed. Campinas: Papirus, 2002.

PIMENTA, S. G.; LIMA, M. S. L. Estágio e docência. 3. ed. São Paulo: Cortez, 2004.

ROITMAN, I. Educação científica: quando mais cedo melhor. Brasília: RITLA, 2007.

Disponível em: <http://www.dominiopublico.gov.br/pesquisa/

DetalheObraForm.do?select_action=\&co_obra=103162 >. Acesso em: 24 jun. 2009.

SEVERINO, A. J. Ensino e pesquisa na docência universitária: caminhos para a integração. São Paulo: FEUSP, 2008.

VALE, J. M. F. Educação científica e sociedade. In: NARDI, R. (Org.). Questões atuais no ensino de ciências. São Paulo: Escrituras, 2005. p. 1-8.

WERTHEIN, J.; CUNHA, C. da. A educação científica como direito de todos. In: WERTHEIN, J. Educação científica e desenvolvimento: o que pensam os cientistas. Brasília: UNESCO; Instituto Sangari, 2005. p. 15-46.

Artigo recebido em 08/06/2011. Aceito em 15/02/2012. 